\title{
Desafios Éticos no exercício da profissão contábil: Uma análise da percepção dos profissionais de Contabilidade
}

\author{
Vitória Libório Dias Nunes ${ }^{1}$, Josaias Santana dos Santos ${ }^{2}$, Nadielson Barbosa da França ${ }^{3}$, \\ Joao Carlos Hipolito Bernardes do Nascimento ${ }^{4}$, Clarissa Vassem Campos ${ }^{5}$
}

Resumo: A presente pesquisa teve como objetivo analisar a percepção dos profissionais de contabilidade do município de Petrolina - PE acerca das dificuldades no cumprimento ao código de ética profissional. A pesquisa se classifica como predominantemente quantitativa. Foi aplicado um questionário estruturado com 24 (vinte e quatro) questões, para uma amostra de 103 (cento e três) profissionais de contabilidade, sobre o grau de dificuldade no cumprimento das determinações do Código de Ética Profissional do Contador. Os resultados evidenciam os profissionais possuem dificuldade em cumprir alguns deveres, concluindo-se, também, que o grau de conhecimento sobre o código de ética de cerca de $40 \%$ dos entrevistados não é aprofundado. Conclui-se, por fim, pela necessidade de melhorar a linguagem do código de ética pra melhor entendimento por parte dos contadores.

Palavras-chave: Ética Profissional. Profissionais de Contabilidade. Código de Ética Profissional do Contador.

\section{Ethical Challenges in the exercise of the accounting profession: An analysis of the perception of Accounting professionals}

\begin{abstract}
The present research had the objective of analyzing the perception of accounting professionals of the municipality of Petrolina - PE about the difficulties in complying with the code of professional ethics. The research is classified as predominantly quantitative. A structured questionnaire was applied with 24 (twenty four) questions, for a sample of 103 (one hundred and three) accounting professionals, about the degree of difficulty in complying with the determinations of the Professional Code of Ethics of the Accountant. The results show that professionals have difficulty fulfilling some of their duties, and it is also concluded that the degree of knowledge about the code of ethics of about $40 \%$ of respondents is not deepened. Finally, it is concluded by the need to improve the language of the code of ethics for better understanding by accountants.
\end{abstract}

Keywords: Professional Ethics. Accounting Professionals. Code of Professional Ethics of the Accountant.

\footnotetext{
${ }^{1}$ Graduanda em Ciências Contábeis, atua na área contábil empresarial. vitoria.liborio0806@ gmail.com;

${ }^{2}$ Mestre em Ciências Contábeis pela Fucape Bussines School - FUCAPE, Vitória - ES. Graduação em Ciências Contábeis pela Faculdade de Ciências Aplicadas e Sociais de Petrolina - FACAPE e Especialização em Gestão da Administração Pública pela Universidade Castelo Branco - UCB, Rio de Janeiro - RJ. Servidor Público Federal, da Universidade Federal do Vale do São Francisco - UNIVASF. É Professor Assistente na FACAPE, josaias.santana@ facape.br;

${ }^{3}$ Graduado em Direito pela Universidade do Estado da Bahia, Mestrando em Dinâmicas de Desenvolvimento do Semiárido, pela Universidade Federal do Vale do São Francisco e Pós-graduado em direito público pela Escola Superior de Magistratura de Pernambuco. É Advogado e Professor do Curso de Direito da Faculdade de Ciências Aplicadas e Sociais de Petrolina - FACAPE. nadielson@ gmail.com;

${ }^{4}$ Doutor em Ciências Contábeis pela Universidade Federal do Rio de Janeiro (UFRJ), Mestre em Contabilidade pela Fundação Instituto Capixaba de Pesquisas em Contabilidade, Economia e Finanças (FUCAPE), Especialista em Gestão de Recursos Humanos pela Universidade de Pernambuco - UPE, MBA em Gestão de Negócios pela Escola de Engenharia e Agrimensura da Bahia - EEA, graduado em Ciências Contábeis pela Faculdade de Ciências Aplicadas e Sociais de Petrolina e em Tecnologia em Processos Gerenciais pela Universidade Norte do Paraná. Docente do curso de Bacharelado em Administração de Empresas (Campus Amílcar Ferreira Sobral), do Programa de PósGraduação em Gestão Pública da UFPI e do Programa de Pós-Graduação em Administração Pública (PROFIAP), ambos na disciplina de Orçamento Público. joaohipolito@ufpi.edu.br;

${ }^{5}$ Mestre em Ciências Contábeis pela FUCAPE - Fundação Instituto Capixaba de Pesquisa em Contabilidade, Economia e Finanças (2016), tendo como linha de pesquisa Contabilidade e Controladoria Aplicada ao Setor Público. Graduada em Ciências Contábeis pela UFES Universidade Federal do Espírito Santo. clarissa_vassem@hotmail.com.
} 


\section{Introdução}

A ética é um conhecimento que contribui com a orientação do comportamento humano social: o como viver e o como devo agir. Assim, a ética é uma disciplina filosófica que tem como fundamento a reflexão de forma sistemática e aprofundada sobre o comportamento humano nas diversas formas de manifestações e atuações em sociedade (VALLS, 1994).

Nesse sentido, a ética, é considerada um conjunto de princípios que solidifica a diversidade normativa postulada nos mais diversos códigos e que traduz o sentido supremo da existência humana à obrigatoriedade moral expressa pelo dever ético, de acordo com Nalini (2013, p. 28), "o objetivo da ética é a moral”. As ações delimitadas moralmente pelos códigos não se distinguem melhores do que outras, apenas norteiam e justificam a ação individual e social do profissional.

A ética se distingue dos problemas morais cotidianos por sua característica de generalização no campo do conhecimento. Seus princípios têm legitimidade e aplicação universais. Enquanto a moral tem aprovação mais específica para o comportamento práticomoral qualificando determinados atos pelo julgamento e avaliação dos mesmos; emitem juízos morais de aprovação ou desaprovação de si mesmos e dos outros.

Na modernidade o problema da teoria ética é a seguinte pergunta: o que devo fazer? Toda dificuldade de resposta está na busca do princípio moral que corresponda adequadamente aos anseios e desejos do homem moderno. A tarefa ética então seria fundamentar esse princípio que justifique a ação moral frente a inúmeros desafios sociais, econômicos, políticos.

No campo profissional, a ética é entendida como conjunto de normas e princípios que norteia uma classe profissional para a prática das suas atividades, buscando, assim, um padrão na conduta profissional, às vezes se tornando uma tarefa não muito fácil.

Os Códigos de Ética são estabelecidos pelas categorias profissionais de forma democrática, atendendo as suas especificidades, sem apelo ao dogmatismo imposto, visam orientar o exercício da profissão na eficácia da prática ética.

Na profissão contábil, a ética é estabelecida pelo Conselho Federal de Contabilidade, mais precisamente pelo Código de Ética do Profissional do Contador. Sendo esse código de ética um guia para conduzir as atitudes dos profissionais contábeis mostrando seus direitos e deveres, assim direcionado para comportamentos de forma corretos na profissão. 
A partir do que foi discutido acerca da ética, emerge-se o seguinte pergunta: Qual a percepção dos profissionais de contabilidade sobre as dificuldades no cumprimento do código de ética da profissão contábil? Tendo a pesquisa como objetivo analisar a percepção dos profissionais de contabilidade do município de Petrolina - PE acerca das dificuldades no cumprimento ao código ética profissional.

O estudo se justifica, pois visa examinar o desempenho do profissional Contábil frente aos desafios éticos do mundo globalizado. A importância do presente trabalho reside em esclarecer para a classe dos profissionais de contabilidade, gerenciadores de informações, qual a melhor forma para lidar com os desafios éticos e também mostrar que o Código de Ética pode ser uma peça fundamental de consulta diante dos desafios.

\section{Referencial Teórico}

\section{A Ética como requisito Ético - Profissional}

A palavra profissão, de acordo com Sá (2015, p. 147), "provém do latim professione, [...] o conceito da profissão [...] representa trabalho que se pratica com habitualidade a serviço de terceiros, ou seja, prática constante de um ofício".

Sá (2015) em seu trabalho pontua conceitos importantes sobre a profissão contábil e distingue os pontos de Cuvillier: que é através da profissão que as pessoas se realizam, usando da capacidade e da inteligência para vencer as dificuldades encontradas no exercício de qualquer profissão. É por meio da profissão que o homem se realiza na tarefa de ser útil a sociedade.

O dever de conhecer e "buscar a perfeição na execução de uma tarefa é um dever profissional que depende do conhecimento e da aplicação plena do mesmo" (Sá, 2015, p. 170). Então, a sua prática profissional é dependente das legislações e de muita atenção as modificações das leis, que demanda uma atualização constante - das leis e dos avanços tecnológicos. O que não deixa de ser um desafio para o novo perfil do contador, sobretudo um desafio ético perante a ciência.

Ademais, Sá (2015, p. 68) ilustra que “coisa alguma é ética se é produzida com prejuízo de alguém, com a intenção de um subjetivismo acentuado e pernicioso". Ponderando- 
se que a subjetividade é construída por diversos agenciamentos no ambiente cultural e social: de lado positivo e outro negativo, assim, a ética como intenção subjetiva individual, corre o risco em seus efeitos.

Vale recorrer à obra de Morin (2005, p. 46), quando afirma que "mesmo a ação boa pode carregar um futuro funesto; mesmo pacifica ela pode conter um futuro perigoso". Completando o autor afirma que "(...) aos riscos de desastre da boa intenção e da boa ação somam-se a incerteza absoluta do resultado final da ação ética". E que "nenhuma ação tem a garantia de seguir o rumo da sua intenção". (idem).

De acordo com o Código o profissional deve exercer suas atividades com honestidade, independência e lisura, fundamentos postuladores da contabilidade. Quanto a violação algumas práticas são empreendidas por profissionais da Contabilidade e de acordo com Conselho Federal de Contabilidade (2003) cita-se que são consideradas como infração as seguintes ações:

1.Angariar clientes por meio de agenciador;

2.Inexecução dos serviços contábeis para os quais foi expressamente contratado;

3.Inexecução de serviços contábeis obrigatórios;

4.Adulteração ou manipulação fraudulenta na escrita ou em documentos, com o fim de favorecer a si mesmo ou a clientes;

5.Apropriação indébita;

6.Incapacidade técnica;

7.Incapacidade técnica em virtude de erros reiterados (precedidas de processo de sindicância);

8.Aviltamento de honorários;

9.Concorrência desleal;

10.Anúncio que resulte na diminuição do colega ou de organização contábil;

11.Retenção abusiva, danificação ou extravio de livros ou documentos contábeis, comprovadamente, entregue aos cuidados do contabilista. (CFC, 2003, p. 29;31)

Fica evidente que diante da possibilidade de cometer as infrações em comento por parte dos profissionais da Contabilidade - a ética profissional perderia toda sua validade e necessidade perante o social, o status de cientificidade e ainda não seria considerada como um desafio de vida - a possiblidade de agir e de ser ético. (grifos nossos).

Testar a validade e valor da ética pela transgressão da própria ética e ao sistema de normas do Código de Ética da Profissão, pela experiência subjetiva e profissional, sem dúvida seria a escolha do pior caminho. Também é verdade que a experiência se constitui a fonte de todo o conhecimento pelo exercício da faculdade de conhecer. Assim se estabelece a relação sujeito/objeto. Nesse contexto Lisboa (1997) diz: 
No meio profissional, o argumento mais relevante que pode ser utilizado para que todos compreendam a importância da ética, válido para qualquer profissão, é o de que, caso a sociedade em geral não perceba a disposição dos profissionais em proteger os valores éticos, certamente ela passará a não acreditar na profissão (LISBOA 1997, p. 54)

O Código de Ética Profissional (2011, p. 3) relata que, "a ética deve ser a base da construção da vida profissional. Exercer a profissão com zelo, diligência e honestidade é dever de todo o profissional da contabilidade comprometido com a sociedade, com os colegas e a classe".

A ética em nenhuma situação pode ser deixada de lado. Segundo Sá (2015), o valor ético deve sempre acompanhar os serviços prestados pelos profissionais assim mostra uma boa qualidade. Quando não se tem ética, mas somente o conhecimento técnico da profissão, isso faz com que o campo de trabalho tenha conflito.

\section{Código de Ética Profissional do Contador}

Silva (2018) fala que “A contabilidade, como qualquer outra profissão possui seu código de ética próprio. É nesse documento que os contadores se baseiam para agir dentro das normas com colegas, clientes e sociedade".

Segundo Lisboa (1997, p.61) um código de ética deve obter condutas e obrigações aplicáveis aos contadores organizado em, no mínimo, quatro áreas: competência, sigilo, integridade e objetividade.

O órgão de maior representação da categoria contabilística, o Conselho Federal de Contabilidade, estabeleceu o Código de Ética Profissional do Contabilista (CEPC) de acordo com a Resolução n 803/96, de 10 de dezembro de 1996 e tem por finalidade "fixar a forma pela qual se deve conduzir os profissionais da contabilidade, quando no exercício profissional e nos assuntos relacionados à profissão e à classe". Passando pelas seguintes alterações:

- Resolução 1997/000819 que trata do recurso ex officio processo ético (D.O.U de 13/01/1997).

- Resolução 2002/000942 - que altera o CEPC (D.O.U de 04/09/2002)

- Resolução 2002/000950 que altera o CEPC (D.O.U de 16/12/2002) 
- Resolução 2010/001307 que Altera dispositivos da Resolução CFC n 803/96 (D.O.U de 14/12/2010).

O Código de Ética Profissional do Contador, em seu primeiro capítulo transcorre a respeito dos objetivos; o segundo relata sobre os deveres e obrigações; o terceiro acerca dos valores cobrados pelos profissionais; o quarto sobre os deveres inter-profissionais da classe; o quinto a respeito de penalidades; e o último sobre disposições gerais, segundo (CAMPOS; SOUZA; LIMA, 2013).

De acordo com Lisboa (1997), o Código de Ética Profissional do Contabilista detém os princípios éticos funcionais à sua classe profissional, que dizem respeito a seus deveres perante a sociedade e responsabilidades da profissão, integridade com relação ao cliente e conservação da imagem profissional, mantendo-se sempre atualizado no tocante às inovações na área, observando também as normas de atuação profissional e ainda constatando o respeito para com os colegas de classe.

Desse modo, Lisboa (1997) afirma que muitas vezes os contadores no âmbito de suas atividades deparam-se com extremos em sua profissão, são eles: o quesito ético, que se refere à estruturação de um problema, e a questão do impasse ético, que dispõe a maneira que se dará a resolução de tal problema que não ocorre de modo claro, pois compõe-se de alternativas conflitantes.

O Código de Ética tem influência na pratica profissional do contador visto que decorre de seus princípios os conhecimentos sobre os seus direito e deveres. A maioria dos contadores tem o código de ética como um guia nas condutas profissionais, mas tem aquela minoria que acha desnecessário seguir tudo aquilo que está escrito no Código de Ética Profissional (ALVES; LISBOA; WEFFORT; ANTUNES, 2007).

\section{Conflitos Éticos na Profissão Contábil}

Para Magro, Silva e Zonatto (2018) o que ajuda nos dilemas éticos no dia a dia dos profissionais contábeis é como foi passado a disciplina de ética para os profissionais se foi dada a devia importância, pois é através dessa disciplina que mostra como deve ser a conduta do profissional no exercício da sua profissão.

Kant confirma que ser moral para dar sentido à vida é, "a intenção moral em luta" (Cap. III, do livro I), pois um esforço em luta, em conflito e Sá, (2015, p.128) autentica ao 
dizer que "o valor do esforço humano é, pois, variável de acordo com seu alcance em face da comunidade". Ilustrando a questão formulada pode-se mencionar o fenômeno da corrupção que tem nos seus efeitos um largo alcance social.

Seguindo por este entendimento ser moral é a aquisição de princípios morais garantidores de uma vida feliz confirmada desde a Grécia antiga por seus filósofos. Ainda, conforme Cortina e Martinez (2005, p. 31), "ser moral é sinônimo de aplicar o intelecto à tarefa de descobrir e escolher em cada momento os meios oportunos para alcançar uma plena, feliz, globalmente satisfatória. Nesse sentido, a base para conduzir-se moralmente é uma correta deliberação, ou seja, um uso adequado da racionalidade, entendida aqui como racionalidade prudencial" (grifos do autor).

Afirmando que a conduta moral pessoal faz sua aplicação necessária de forma igual nos negócios, Nash (2000), ainda explana que não há separação de padrões de moral, sendo o diferencial o contexto de cada negócio, assim como as peculiaridades de cada um. No entanto, de forma frequente, no âmbito das empresas os indivíduos se comportam de acordo com seus interesses, convertendo em função desses interesses, as preferências de suas atitudes morais.

Referente a Contabilidade, por exemplo, onde o profissional é portador de todos os dados das instituições administrando seus meios, pode-se afirmar que há o conflito de interesses entre a necessidade do cliente e execução coerente de suas atividades no tocante às normatizações de sua profissão (CAMPOS; SOUZA; LIMA, 2013).

Na visão de Campos, Souza e Lima (2013), o contexto em que uma consultoria especializada é de grande importância para a estabilidade de uma instituição empresarial encontra-se de forma recorrente. Sendo assim, este profissional ficar atento às pretensões de seus clientes com qualidade e capacitação exemplares, visto que este tem de imagem de um contador um "provedor de milagres". Com base nisso é necessário que o profissional se mantenha atualizado, já que a informação contábil deve se adequar as necessidades de seus usuários, com transparência sem erros e sem ser tendenciosa.

Dados contabilísticos malfeitos, não expõem soluções, nem obtém êxito em na satisfação do cliente X com relação ao profissional de contabilidade, Jimenez (1997) fala que de forma frequente o profissional administra lugares de responsabilidade, nos quais tem que lidar com inúmeros bens, isso quer dizer que se faz necessário uma fundamentação moral, que o faça consciente de seus deveres e da extensão humana e social de sua função. 


\section{Metodologia}

Em relação à classificação será descritiva, pois buscar apresentar as informações de forma compressível, através de tabelas e gráficos. Segundo Cervo e Bervian (2002) esse tipo de pesquisa, analisa os fatos sem alterar os dados, assim constatando a frequência que ocorre o fenômeno, a relação com o meio e as características.

Quanto aos procedimentos, a pesquisa será bibliográfica para fins do referencial, pois segundo Lakatos e Marconi (2009, p. 185), “as pesquisas bibliográficas ou de fontes secundárias, abrangem toda a bibliografia já tornada pública em relação ao tema de estudo, desde publicações avulsas, boletins, jornais, revistas, livros”. A coleta de dados, se deu por meio de aplicação de questionário segundo Gil (2011, p.121) "O questionário é uma técnica de investigação composta por um conjunto de questões que são submetidas a pessoas com o propósito de obter informações."

O problema pretende ser abordado de forma predominantemente quantitativa, pois para Collis e Hussey (2005, p. 26) fala que "envolve coletar e analisar dados numéricos e aplicar testes estatísticos".

O questionário estruturado foi aplicado com os contadores, de modo que as informações sejam apresentadas por meio de gráficos, para que chegue no resultado final esperado. Na pesquisa utilizou-se o universo de 481 profissionais contábeis, sendo que amostra do estudo vai ser representada por 103 profissionais de contabilidade do universo do município de Petrolina-PE, essas informações foram coletadas no CRCPE (onde foi utilizada uma amostra não probabilística).

A coleta de dados segundo Barros e Lehfeld (2007 p.105) "É á onde se questiona a realidade conseguindo dados através das aplicações técnicas"). O questionário que foi utilizado no estudo vai ser desenvolvido para os profissionais de contabilidade, terá 24 questões que abordara a problemática.

A pesquisa foi aplicada tanto presencial como virtualmente e elaborada através da ferramenta google docs, instrumento do site google que ajuda na criação de enquetes e entrevistas. Para coletar os dados foi necessário em alguns casos marcar entrevistas com os profissionais de contabilidade de Petrolina-PE, já outros responderam através do link enviados por e-mail para resolução do questionário através desses métodos obteve -se as respostas para chegar assim ao resultado final esperado para a pesquisa. 


\section{Resultados e Análise}

O número de profissionais registrados no Conselho Regional de Contabilidade de Pernambuco na cidade de Petrolina - PE é de 481 (quatrocentos e oitenta um); destes, 103 (cento e três) profissionais responderam o questionário, segundo o critério de acessibilidade.

Para definição da amostra necessária, utilizou-se a seguinte fórmula:

$$
n=\frac{N \cdot Z^{2} \cdot p \cdot(1-p)}{Z^{2} \cdot p \cdot(1-p)+e^{2} \cdot(N-1)}
$$

Onde: $\mathrm{N}-$ população $=481$

$Z$ - variável normal padronizada associada ao nível de confiança $=95 \%$

$\mathrm{p}$ - verdadeira probabilidade do evento $=50 \%$

e - erro amostral $=10 \%$

$\mathrm{n}-$ amostra calculada $=81$

O questionário aplicado a esses profissionais foi composto por 24 (vinte e quatro) perguntas todas fechadas, sendo 6 (seis) sobre as características descritivas do profissional de contabilidade, e 18 (dezoito) sobre as dificuldades encontradas pelos profissionais no cumprimento do código de ética profissional.

A princípio foi analisado o perfil dos entrevistados, primeiramente foram perguntados sobre a idade, verificou-se, que a maior parte dos entrevistados tem entre 30 a 40 anos, sendo $35 \%$ dos profissionais, $29 \%$ de 20 a 30 anos, $27 \%$ de 40 a 50 anos, enquanto apenas $9 \%$ da amostra possui idade acima de 50 anos.

Sobre o gênero, percebeu-se que as maiorias dos profissionais que responderam os questionários são do sexo feminino com $62 \%$, enquanto $38 \%$ são do sexo masculino. Ao questionar sobre a categoria profissional, por parte dos entrevistados, apuraram-se os dados a seguir: 
Gráfico 1: Categoria Profissional Dos Entrevistados

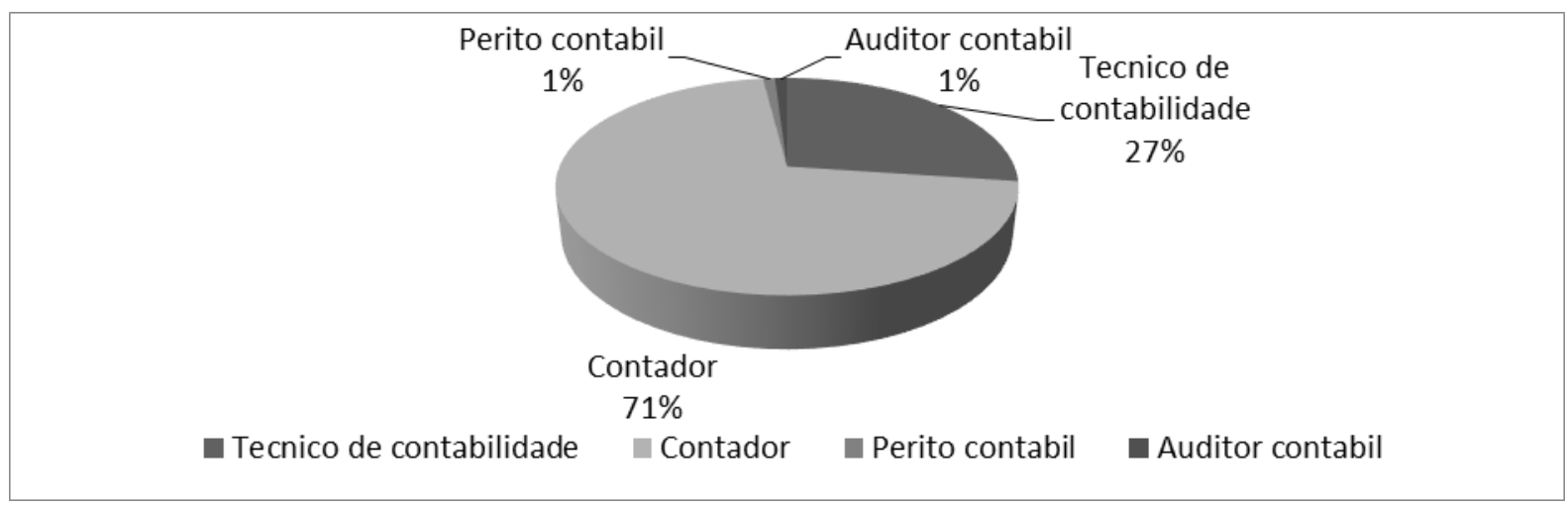

Fonte: Elaborado pelos autores.

No Gráfico 1 observou -se que $71 \%$ dos entrevistados são contadores, que possuem bacharel no curso de ciências contábeis, enquanto que $27 \%$ são técnicos de contabilidade, $1 \%$ auditor contábil e $1 \%$ perito contábil, ou seja, a maior representatividade da amostra, é atribuída aos contadores, profissionais que possuem o ensino superior completo.

Sabe-se que o profissional contábil, ou de qualquer que seja a área de atuação pode trabalhar para si mesmo, ter seu próprio negócio, ou até mesmo ser empregado de alguma empresa. Ao questionar sobre a atuação profissional dos entrevistados, obteve-se os seguintes resultados:

Gráfico 2: Atuação Profissional dos Entrevistados

\begin{tabular}{|c|c|c|}
\hline \\
$40 \%$ \\
Empresário Contabil
\end{tabular}

Fonte: Elaborado pelos autores.

Observou-se no Gráfico 2, que duas áreas de atuação profissional apresentaram-se de forma mais representativa, que foram os profissionais celetistas e o empresário contábil, com 
$40 \%$ e $41 \%$ respectivamente. Isso demonstra que as maiores partes dos profissionais possuem seu próprio negócio, ou trabalham de carteira assinada em empresas da região.

Sobre o tempo de experiência profissional na área foi encontrado os seguintes resultados:

Gráfico 3: Experiência Profissional na Área Contábil

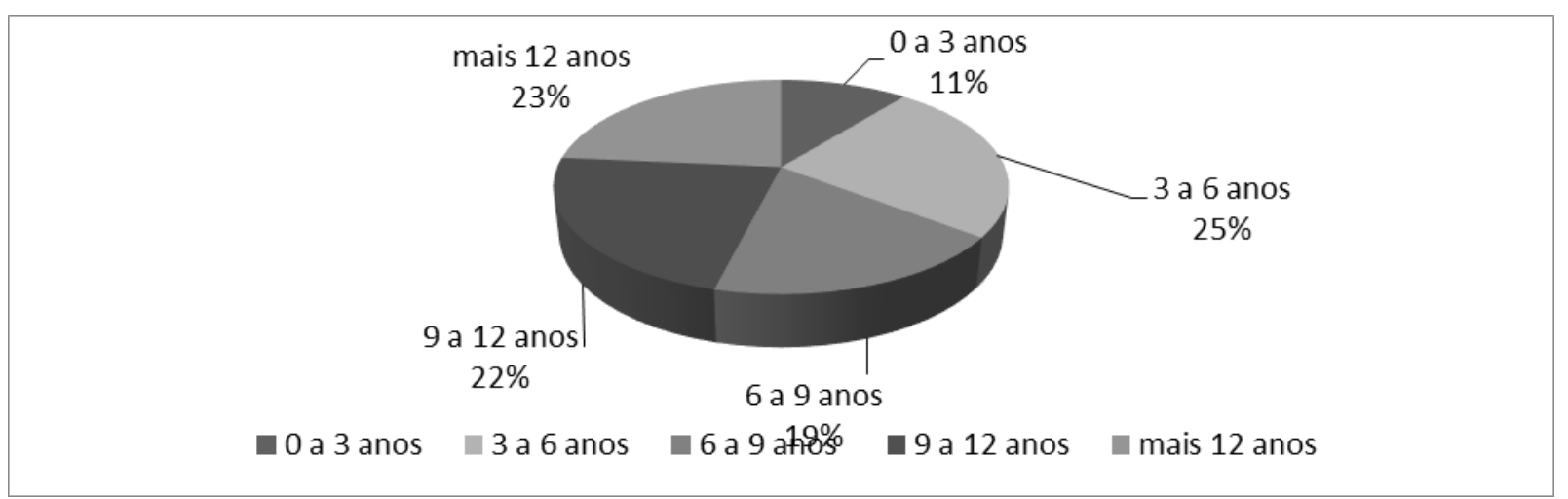

Fonte: Elaborado pelos autores.

A partir do Gráfico 3 é notório que 1/4 dos entrevistados (cerca de $25 \%$ ) possuem experiência de 3 a 6 anos na área contábil, esse quantitativo de ano, foi o que apresentou uma maior representatividade. Já profissionais recém-formados, e que começou a atuar na área a menos de 3 anos, representaram 11\% da amostra. No geral, percebe-se através do Gráfico 3, que a maior parte dos profissionais contábeis, atuam na área de 0 a 12 anos.

O próximo questionamento foi sobre o conhecimento do código de ética, onde se encontrou os seguintes resultados: $46 \%$ dos profissionais entrevistados conhecem bem o código de ética do contador, mas por outro lado houve uma porcentagem de $44 \%$ dos entrevistados que afirmaram conhecer pouco e $10 \%$ desconhecem o código. Bencke e Martins (2018) fala que uma forma de fazer com que os profissionais contábeis tenham o conhecimento necessário sobre o código de ética é investindo mais nos estudos sobre ética na formação acadêmica.

A segunda parte do questionário foi composta por 18 (dezoito) questões fechadas a respeito do grau de dificuldade no cumprimento das determinações do Código de Ética Profissional do Contador.

$\mathrm{Na}$ sequência são apresentados os resultados em quadros que estão divididos por grupos de semelhanças entre os deveres. Os deveres foram postos no questionário, e pediu-se 
para os profissionais relacionar através de uma escala de 1 a 10, o nível de dificuldade encontrado para seguir o que estabelece o código de ética, onde 1 é classificado como nenhuma dificuldade, e 10 é classificado como muita dificuldade.

O primeiro grupo de deveres foi o sobre como o profissional contábil deve exercer a profissão. No quadro a seguir estão as médias da percepção de dificuldade encontrada pelos contadores entrevistados.

Quadro 1: Como O Profissional Contábil Deve Exercer A Profissão

\begin{tabular}{|c|c|c|c|}
\hline \multicolumn{2}{|c|}{$\begin{array}{l}\text { Exercer a profissão com zelo, diligência, } \\
\text { honestidade e capacidade técnica, observando } \\
\text { as Normas de Contabilidade e a legislação, } \\
\text { resguardando o interesse público, os } \\
\text { interesses de seus clientes e/ou empregadores, } \\
\text { sem prejuízo da dignidade e independência } \\
\text { profissionais. }\end{array}$} & $\begin{array}{l}\text { Recusar sua indicação em } \\
\text { trabalho quando reconheça } \\
\text { não se achar capacitado } \\
\text { para a especialização } \\
\text { requerida. }\end{array}$ & $\begin{array}{l}\text { Guardar sigilo sobre o que souber } \\
\text { em razão do exercício } \\
\text { profissional, inclusive no âmbito } \\
\text { do serviço público (ressalvados } \\
\text { os casos previstos em lei ou } \\
\text { quando solicitado por autoridades } \\
\text { competentes). }\end{array}$ \\
\hline Média & 4,01 & 3,78 & 3,4 \\
\hline Mediana & 4 & 3 & 2 \\
\hline Moda & 1 & 1 & 1 \\
\hline Desvio Padrão & 2,99 & 3,03 & 3,0 \\
\hline Curtose & 0,90 & 0,74 & 0,60 \\
\hline Assimetria & 0,56 & 0,73 & 0,85 \\
\hline
\end{tabular}

Fonte: Elaborado pelos autores.

No Quadro 1 em relação como se deve exercer a profissão, verificou-se que as médias em dois deveres foi alta considerando que é um dever primordial, chegando a uma média 4 na primeira regra, e 3,8 na segunda. Já no último dever relacionado, observou-se que os entrevistados têm uma dificuldade menor na prática esse dever.

O outro grupo de deveres foi o sobre os argumentos e competência necessários aos profissionais contábeis, ao exercer a profissão. O Quadro 2 apresenta a estatística descritiva, e as respectivas médias da percepção de dificuldade encontradas pelos contadores nesses deveres: 
Quadro 2: Argumentos e Competência Necessários aos Profissionais Contábeis

\begin{tabular}{|c|c|c|}
\hline \multicolumn{2}{|c|}{$\begin{array}{c}\text { Abster-se de expender argumentos ou dar a conhecer sua } \\
\text { convicção pessoal sobre os direitos de quaisquer das partes } \\
\text { interessadas, ou da justiça da causa em que estiver servindo, } \\
\text { mantendo seu trabalho no âmbito técnico e limitado ao } \\
\text { alcance do trabalho. }\end{array}$} & $\begin{array}{c}\text { Zelar pela sua competência exclusiva na } \\
\text { orientação técnica dos serviços a seu cargo, } \\
\text { abstendo-se de emitir qualquer opinião em } \\
\text { trabalho de outro contador, sem que tenha sido } \\
\text { contratado para tal. }\end{array}$ \\
\hline $\begin{array}{c}\text { Média } \\
\text { Mediana }\end{array}$ & $\begin{array}{c}\text { (a) } \\
\text { Moda }\end{array}$ & 3,8 \\
Desvio Padrão & 2,9 & 1 \\
Curtose & 0,67 & 2,8 \\
Assimetria & 0,63 & 0,81 \\
\hline
\end{tabular}

Fonte: Elaborado pelos autores.

Em relação ao Quadro 2, verificou-se que quanto a competência e argumentos que o profissional contábil, precisa ter para exercer suas atividades, assim como os argumentos e a convicção pessoal sobre seus a justiça, houve uma certa dificuldade por parte dos profissionais entrevistados, já que a média encontrada nesse quesito foi de 4.

Sobre a competência na orientação técnica, também foi perceptível que os profissionais declaram ter dificuldade, já que se encontrou uma média de 3,8, concluindo assim que na percepção dos contadores, esses dois deveres são difíceis de serem seguidos.

Questionou-se também, sobre a comunicação das funções dos profissionais contábeis, tanto entre cliente e contador, como também entre colegas de profissionais, onde foram encontradas as seguintes estatísticas descritivas:

Quadro 3: Comunicação das Funções dos Profissionais

\begin{tabular}{|c|c|c|}
\hline \multicolumn{2}{|c|}{$\begin{array}{c}\text { Sobre renunciar às funções que exerce, logo que se positive } \\
\text { falta de confiança por parte do cliente ou empregador e } \\
\text { vice-versa, a quem deve notificar por escrito com } \\
\text { antecedência. }\end{array}$} & $\begin{array}{l}\text { Quando substituído em suas funções, informar ao } \\
\text { substituto sobre fatos que devam chegar ao } \\
\text { conhecimento desse, a fim de habilitá-lo para o } \\
\text { bom desempenho das funções a serem exercidas. }\end{array}$ \\
\hline Média & 3,6 & 3,5 \\
\hline Mediana & 3 & 3 \\
\hline Moda & 1 & 1 \\
\hline Desvio Padrão & 2,9 & 2,8 \\
\hline Curtose & 0,85 & 0,61 \\
\hline Assimetria & 0,71 & 0,79 \\
\hline
\end{tabular}

Fonte: Elaborado pelos autores. 
Analisou-se que a um pouco de dificuldade em relação a comunicação entre os profissionais, sendo que 3,7 é a média de dificuldade pra a renúncia do cargo quando não passa confiança pra os clientes, e a segunda que trata das informações que deve ser passada para os substitutos, obteve-se uma média de 3,5.

Sobre a comunicação e documentos necessários que o contador precisa estar de posse pra argumentar em quaisquer circunstâncias, as médias da percepção de dificuldade encontradas pelos contadores nessas regras, estão descritas no Quadro 4:

Quadro 4: Comunicação e Documentos para emitir Opinião Própria

\begin{tabular}{|c|c|c|}
\hline $\begin{array}{c}\text { Comunicar, desde logo, ao cliente ou empregador, em } \\
\text { documento reservado, eventual circunstância adversa que possa } \\
\text { gerar riscos ameaças ou influir na decisão daqueles que são } \\
\text { usuários dos relatórios e serviços contábeis como um todo. }\end{array}$ & $\begin{array}{c}\text { Despender os esforços necessários e se munir } \\
\text { de documentos e informações para inteirar-se } \\
\text { de todas as circunstâncias, antes de emitir } \\
\text { opinião sobre qualquer caso. }\end{array}$ \\
\hline Média & 3,6 & 3,5 \\
Mediana & 3 & 3 \\
Moda & 1 & 1 \\
Desvio Padrão & 2,9 & 2,8 \\
Curtose & $-0,85$ & 0,61 \\
Assimetria & 0,719 & 0,79 \\
\hline
\end{tabular}

Fonte: Elaborado pelos autores.

Observou-se no Quadro 4 que a comunicação e documentos que os profissionais precisam estar de posse, antes de obter qualquer opinião, os entrevistados responderam em sua maioria que há um nível de dificuldade de quase 4, numa escala de 1 a 10, ou seja, ainda há uma certa dificuldade por parte dos profissionais contábeis, em ter posse dessa documentação, e isso deve ser influenciado por inúmeros fatores, inclusive a falta de liberação de alguns documentos por parte dos clientes.

Sobre o quadro 5, foram encontrados os seguintes resultados: 
Quadro 5: Solidário com a defesa da dignidade profissional, cumprir os programas de educação profissional e fiscalização do exercício profissional

\begin{tabular}{|c|c|c|c|}
\hline \multicolumn{2}{|c|}{$\begin{array}{l}\text { Ser solidário com os movimentos de defesa da } \\
\text { dignidade profissional, seja propugnando por } \\
\text { remuneração condigna, seja zelando por } \\
\text { condições de trabalho compatíveis com o } \\
\text { exercício ético-profissional da Contabilidade e } \\
\text { seu aprimoramento técnico. }\end{array}$} & $\begin{array}{l}\text { Cumprir os Programas de } \\
\text { Educação Profissional } \\
\text { Continuada de acordo com o } \\
\text { estabelecido pelo CFC. }\end{array}$ & $\begin{array}{l}\text { Dificuldade em atender à } \\
\text { fiscalização do exercício } \\
\text { profissional e disponibilizar } \\
\text { papéis de trabalho, relatórios } \\
\text { e outros documentos } \\
\text { solicitados } \\
\end{array}$ \\
\hline Média & 3,7 & 4,0 & 3,8 \\
\hline Mediana & 3 & 4 & 3 \\
\hline Moda & 1 & 1 & 1 \\
\hline Desvio Padrão & 2,9 & 2,9 & 3,0 \\
\hline Curtose & 0,73 & 0,9 & 0,79 \\
\hline Assimetria & 0,68 & 0,51 & 0,70 \\
\hline
\end{tabular}

Fonte: Elaborado pelos autores.

Os profissionais ao ser questionados em relação a ser solidários com os movimentos de defesa profissional, mostrou uma percepção de dificuldade alta tendo média 3,7, ou seja, ainda há uma certa dificuldade por parte dos profissionais, em ser solidários, tanto na questão de zelo por condições de trabalhos, como também no aprimoramento técnico. Questionados sobre o cumprir dos Programas de Educação Profissional, observou - se as seguintes médias:

Sobre a participação dos programas educativos propostos pelos CRC, observou -se que na percepção dos profissionais existe um contratempo quanto ao comprimento desse dever com média de dificuldade 3,7. Os profissionais ainda questionados se teriam alguma dificuldade em atender à fiscalização do exercício profissional e disponibilizar papéis necessários. Os dados foram dispostos no quadro a

Quanto a fiscalização do exercício profissional analisou-se quer a uma dificuldade na disponibilização de papeis corretos para atender o que a fiscalização está pedindo. Notou-se uma média de 3,8 de dificuldade nesse dever. Nesse quadro estão as medias que foram coletadas sobre os anuncio em qualquer modalidade ou veículo de comunicação dos pacotes de serviços e da diminuição dos colegas de classes. 
Quadro 6: Anúncio em Qualquer Modalidade ou Veículo de Comunicação

\begin{tabular}{|c|c|c|}
\hline $\begin{array}{c}\text { Em observar a vedação quanto a anunciar, em qualquer } \\
\text { modalidade ou veículo de comunicação, o valor dos } \\
\text { serviços ou de pacote de serviços. }\end{array}$ & $\begin{array}{c}\text { De observar a vedação quanto a anunciar, em } \\
\text { qualquer modalidade ou veículo de comunicação, } \\
\text { conteúdo que resulte na diminuição do colega, da } \\
\text { organização contábil ou da classe. }\end{array}$ \\
\hline Média & 3,6 & 3,5 \\
Mediana & 3 & 2 \\
Moda & 1 & 1 \\
Desvio Padrão & 3,0 & 3,0 \\
Curtose & 0,48 & 0,71 \\
Assimetria & 0,85 & 0,80 \\
\hline
\end{tabular}

Fonte: Elaborado pelos autores.

Se tratando de anúncios em qualquer modalidade ou veículo de comunicação tanto dos pacotes de serviços como a diminuição dos colegas de profissão, ao analisar as médias verificou-se que os entrevistados têm pouca dificuldade quanto a cumprir esse dever.

No quadro 7, estão os deveres que diz respeito a conduta do profissional:

Quadro 7: A Conduta do Profissional Contábil

\begin{tabular}{|c|c|c|c|}
\hline \multicolumn{2}{|c|}{$\begin{array}{c}\text { Observar, no que couber, o Código de Defesa } \\
\text { do Consumidor, especialmente no que } \\
\text { concerne à informação adequada clara sobre } \\
\text { os serviços, a serem prestados. }\end{array}$} & $\begin{array}{c}\text { Em relação aos colegas, ter } \\
\text { conduta pautada nos } \\
\text { princípios de consideração, } \\
\text { respeito, apreço, } \\
\text { solidariedade e harmonia da } \\
\text { classe. }\end{array}$ & $\begin{array}{c}\text { De, em relação à classe, prestar } \\
\text { sua cooperação moral, } \\
\text { intelectual e material, salvo } \\
\text { circunstâncias especiais que } \\
\text { justifiquem a sua recusa. }\end{array}$ \\
\hline Média & 3,7 & 3,7 & 3,7 \\
Mediana & 3 & 3 & 3 \\
Moda & 1 & 1 & 1 \\
Desvio Padrão & 3,1 & 3,0 & 3,0 \\
Curtose & $-0,59$ & 0,73 & 0,68 \\
Assimetria & 0,82 & 0,71 & 0,76 \\
\hline
\end{tabular}

Fonte: Elaborado pelos autores.

No Quadro 7, estão os deveres que diz respeito a conduta do profissional, e foi possível notar que os profissionais possuem uma dificuldade na percepção dos entrevistados nessas três regras, já que as médias giraram em torno de 3,7.

E por fim, foram perguntados sobre interpretar corretamente o Código de Ética Profissional do Contador. O quadro a seguir sintetiza os resultados encontrados: 
Quadro 8: Interpretar Corretamente O Código

\begin{tabular}{|c|c|}
\hline \multicolumn{2}{|c|}{ Interpretar corretamente o Código de Ética Profissional do Contador } \\
\hline Média & 3,9 \\
Mediana & 4 \\
Moda & 1 \\
Desvio Padrão & 3,1 \\
Curtose & 0,93 \\
Assimetria & 0,62 \\
\hline
\end{tabular}

Fonte: Elaborado pelos autores.

Ao interpretar o Quadro 8, observou-se uma média de dificuldade alta sendo quase 4, dessa forma mostrando que os entrevistados apontaram dificuldade no entendimento, ou seja, na interpretação do código de ética.

\section{Considerações Finais}

O objetivo da pesquisa foi analisar a percepção dos profissionais de contabilidade, acerca das dificuldades no cumprimento ao código de ética profissional. Tratar de ética é muito mais do que se imagina, decorre do pensar, do agir e do conhecer. Assumir a ética é uma tarefa constante da vida e ser ético antecede toda proposta normativa.

Este trabalho procurou estabelecer maior compreensão a respeito dos desafios da ética existentes no cotidiano profissional do contador, de forma a desvendar o grau de dificuldade na percepção de cada profissional sobre os deveres estabelecidos pelo código de ética do profissional contábil.

Reitera-se que a ausência da ética traz prejuízos ao profissional e a sociedade como todo. Dessa constatação decorre importância do código de ética no exercício da profissão. Nos dias de hoje, além de todas as exigências que um profissional contábil tem, é imprescindível que a ética esteja presente como um requisito básico para a sua atuação como profissional.

Sendo assim tem-se o entendimento que o código de ética do contador serve para orientá-los sobre seus direitos e deveres mais nem sempre todos tem o conhecimento suficiente para conseguir realizar os deveres de forma que não exista nem um tipo de dificuldade. Os dados coletados na pesquisa através de questionário não foram dentro do 
esperado, pois em tese os deveres do código de ética do contador deveriam ser fáceis de cumprir.

Observou-se nos dados analisados que a maioria dos deveres estabelecidos pelo código de ética foi percebido um grau de dificuldade alto, das dezoito questões aplicadas oito se destacaram sendo muito difícil na percepção dos entrevistados. O Quadro 1, onde diz respeito como o profissional contábil deve exercer a profissão, verificou-se que nos dois primeiros deveres a uma percepção de dificuldade muito grande obtendo mais $40 \%$ dos entrevistados.

Percebeu-se também um grau de dificuldade considerável no quadro 2 de $40 \%$ dos entrevistados onde foram questionados sobre os argumentos e competência necessários e nos dois deveres que estão relacionados obteve - se dificuldade por partes dos entrevistados.

Constatou- se também que no quadro $5,38 \%$ dos entrevistados possui dificuldade quanto solidário com a defesa da dignidade profissional. Outra dificuldade que foi encontrada foi no quadro 6onde $38 \%$ dos questionados disserem na percepção deles ter dificuldade em cumprir os Programas de Educação Profisssional.

Percebeu-se no quadro 7, a uma certa dificuldade na percepção dos entrevistados sobre fiscalização do exercício profissional, onde observou-se que $40 \%$ dos profissionais de contabilidade possui um ser tipo de contratempo nesse dever.

Quanto a conduta do profissional contábil mostrado no quadro 9, notou-se que $38 \%$ dos profissionais possui um certo grau dificuldade de atender a fiscalização do exercício profissional e disponibilizar papéis de trabalho, relatório e outros documentos. Por fim no quadro 10, verificou-se que 39\% tem dificuldade de interpretar corretamente o código de ética do contador.

Concluiu - se também que o código de ética do profissional de contabilidade está muito longe da realidade dos contadores nas situações do dia a dia. E percebeu - se também a vontade da maioria dos entrevistados que mude a escrita do código de ética que seja mais objetiva e clara. Justificando assim as dificuldades encontradas nas questões acima.

O trabalho limitou-se a 103 profissionais contábeis do município de Petrolina - PE. Sugere-se para pesquisas futuras ampliar a amostra, aplicando questionários aos profissionais de contabilidade de outros municípios, a fim de realizar um comparativo dos desafios encontrados pelos profissionais quanto ao comprimento dos deveres estabelecido pelo código ética.

505 Id on Line Rev. Mult. Psic. V.13, N. 46 p. 488-507, 2019 - ISSN 1981-1179 Edição eletrônica em http://idonline.emnuvens.com.br/id 


\section{Referências}

ALVES, F. J. D. S.; LISBOA, N. P.; WEFFORT, E. F. J.; ANTUNES, M. T. P. Um estudo empírico sobre a importância do código de ética profissional para o contabilista. Revista Contabilidade \& Finanças - USP, v. 18, p. 58-68, 2007.

BENCKE, Fernando Fantoni; MARTINS, Patrícia Jung. ÉTICA GERAL E PROFISSIONAL EM CONTABILIDADE: UM ESTUDO SOBRE A POSTURA DE DISCENTES E PROFISSIONAIS EM CONTABILIDADE. Revista de Contabilidade da UFBA, Salvador, v. 12, n. 2, p.150-165, mar. 2018. Disponível em: <https://portalseer.ufba.br/index. php/rcontabilidade/article/view/23502>>. Acesso em: 17 dez. 2018.

CAMPOS, S. A.; SOUZA P.; LIMA, M. Ética Na Profissão Contábil: Um Estudo Sobre A Percepção Dos Alunos Sobre A Contribuição Da Disciplina "Ética E Legislação Profissional" Para A Formação Em Ciências Contábeis. In: $8^{\circ}$. Encontro de Produção Científica e Tecnológica- Universidade Federal do Paraná. Campo Mourão, Anais... Campo Mourão: Paraná, 2013.

CERVO, A. L. BERVIAN, P. A. Metodologia científica. 5.ed. São Paulo: Prentice Hall, 2002.

COLLIS, J.; HUSSEY, R. Pesquisa em administração. 2. ed. São Paulo: Bookman, 2005.

CONSELHO FEDERAL DE CONTABILIDADE (CFC). Código de Ética Profissional do Contador. RESOLUÇÃO CFC No 1996/000803 de 20 de novembro de 1996 que Aprova o Código de Ética Profissional do Contador - CEPC, 1996.

RESOLUÇÃO No 1997/000819 de 13 de janeiro de 1997. Restabelece o instituto do recurso "ex officio" na área do Processo Ético. Altera o $§ 2^{\circ}$ do art. 13 do CEPC. Revoga a Resolução CFC nº 677/90 e dá outras providências.

RESOLUÇÃO No 2002/000942 de 04 de setembro de 2002. Altera o Código de Ética Profissional do Contabilista e dá outras providências.

RESOLUÇÃO N ${ }^{\circ}$ 2002/000950 de 16 de dezembro de 2002. Altera o art. 13 do Código de Ética Profissional do Contabilista, aprovado pela Resolução CFC nº 803/96, e o art. $3^{\circ}$ da Resolução CFC nº 819/97, e dá outras providências.

RESOLUÇÃO CFC No 2010/001307 de 09 de dezembro de 2010. Altera dispositivos da Resolução CFC no 803/96, que aprova o Código de Ética Profissional do Contabilista.

CORTINA, A.; MARTÍNINEZ, E. ÉTICA. São Paulo: Loiola, 2005.

GIL, Antonio Carlos. Como elaborar projetos de pesquisa. 4. ed. São Paulo: Atlas, 2008.

JIMENEZ, C. M. Trabalho e convivência: um ensaio de ética profissional. Londrina: UEL, 1997.

LAKATOS, E. M.; MARCONI, M. A. Fundamentos de metodologia científica. 5. ed. São Paulo: Atlas, 2009. 
LISBOA, L. P. (Coord.) FIPCAF. Ética geral e profissional em contabilidade. 2. ed. São Paulo: Atlas, 1997.

MAGRO, Cristian Baú dal; SILVA, Thiago Bruno de Jesus; ZONATTO, Vinicius Costa da Silva. COMO DISCENTES DE CIÊNCIAS CONTÁBEIS REAGEM À DILEMAS ÉTICOS DA PROFISSÃO? Revista Contabilidade Vista \& Revista, Belo Horizonte, v. 28, n. 3, p.5381, set/dez 2017. Disponível em: <https://revistas.face.ufmg.br/index.php/contabilidadevista erevista/article/view/3629>. Acesso em: 18 Dez 2018.

MORIN, E. Educação e complexidade, os sete saberes e outros ensaios. São Paulo: Cortez, 2005.

NALINI, J. R. Ética geral e profissional. 10. ed. Afiliada, 2013.

NASH, L. L. Ética nas organizações. S. Paulo: Makron Books, 2000.

RUIZ, J. A. Metodologia científica: guia para eficiência nos estudos. 6.ed. São Paulo: Atlas, 2010.

SÁ, A. L. Ética profissional. 9. ed. São Paulo: Atlas, 2015.

SILVA, Thiago Vinícius Gonçalves da. A Ética profissional e a percepção de profissionais contábeis. 2018. 25 f. Trabalho de Conclusão de Curso (Graduação em Ciências Contábeis) Universidade Federal de Uberlândia, Uberlândia, 2018.

VALLS, Á.L.M. O que é ética. 9.ed. São Paulo: Brasiliense, 1994.

\section{Como citar este artigo (Formato ABNT):}

NUNES, Vitória Libório Dias; SANTOS, Josaias Santana dos; FRANÇA, Nadielson Barbosa da; NASCIMENTO, Joao Carlos Hipolito Bernardes do; CAMPOS, Clarissa Vassem. Desafios Éticos no exercício da profissão contábil: Uma análise da percepção dos profissionais de Contabilidade. Id on Line Rev.Mult. Psic., 2019, vol.13, n.46, p. 488-507. ISSN: 1981-1179.

Recebido: 28/06/2019;

Aceito: 02/07/2019. 